\title{
An Analysis of the Potential Target Market through the Application of the STP Principle/Model
}

\author{
Johnson Kampamba \\ University of Botswana, Faculty of Engineering and Technology, \\ Department of Civil Engineering, Land Management and Geomatics Section \\ Email: Johnson.kampamba@mopipi.ub.bw
}

\author{
Doi:10.5901/mjss.2015.v6n4s3p324
}

\begin{abstract}
Purpose - The purpose of this paper was to establish and identify the target market of a proposed residential development in Gaborone using the STP strategy. Research design/methodology/approach - Both non-probability and probability sampling techniques were used by applying qualitative and quantitative research methods (interviews and questionnaire) were used to get research data in order to meet the objective of the study. A survey instrument using a self-administered questionnaire was developed and administered to the respondents who were working earning a monthly salary was used in order to meet the minimum qualifying criteria for a home loan being $30 \%$ of one's income to service mortgage payments. Significance - The study is relevant to developers who just develop/invest scarce resources without establishing the need/demand for the product. It will be a lesson learnt for those developers who shun/disregard the input of market research in the process of decision making for housing property development. Findings - The study established that this was the first research of its kind within the housing market. It also revealed that target market identification is critical in market research because it help the developer to minimise the unsystematic and systematic risks which might affect the success of the development project thereby impacting on the profitability of the business. It will also help them appreciate by positioning the product in the minds of the target market through offering the product with features that the customers are looking for. From the developer's point of view, they will be fulfilling the customer's needs by implementing the recommendations and results of the market research report. Once these needs are met and fulfilled, the property listing period is also reduced at the time of marketing the property and customers are identified even before the propduct is developed thus adding value to the business. Originality/value - Based on the key findings, recommendations are made in this paper to improve the market take-up rate through the application of STP analysis.
\end{abstract}

Keywords: Target market, Market segmentation, Housing market, Market analysis, Botswana

\section{Introduction}

The paper is a culmination of a research project which was done in order to establish the potential target market for the house before it is built. The most arching issue is that most developers undertake property investment decision making without establishing the need/demand for that particular product in the market. In Botswana, most developers are not an exception to this problem, despite having invested so much money in the developments they still believe customers should reposition their minds and accept whatever is offered in the property market. This has in the past contributed to loss of market share by such developers and a difficult task for marketing agents because they have to convince prospective customers to making a purchase or leasing decision on a product that they are not satisfied with its features.

The purpose of this paper was to identify the target market for a proposed housing development using the principle of market segmentation, targeting and product position strategy. The research was initiated in view of the office development comprising twelve storeys in the CBD that was developed, two years ago and to date it has not been occupied. The question that one would ask, "is that was the market study undertaken to identify the prospective tenants or buyers of such a large development which was not occupied after two years"?

\section{Background of Botswana}

This is a middle income country which has transformed itself from a least developed nation and maintained one of the world's highest economic growth rates since gaining independence in 1966 through the careful use of foreign direct investment (UNCTAD, 2003). Foreign direct investment (FDI) to Botswana accounted for 17.8 percent of the gross fixed capital formation in contrast to an average of 12.8 percent for all developing countries (World Investment Report, 2010). 
The main contributor to economic growth and development is diamonds which accounts for 80 percent of foreign exchange earnings. Other major contributors to economic growth are cattle farming, tourism and financial services. Matambo (2010) in his budget speech highlighted that the gross domestic product (GDP) for 2009 was at P86.2 billion measured at current prices. The average GDP economic growth for the first three years of NDP 10 was 3.6 percent (Botswana Review, 2014).

\section{Background of the Proposed Property}

The property was designed and constructed based on the features that were obtained from the target market through the application of STP strategy/model in a market survey which this study is the product.

Property Description: A residential plot developed with the main house and outbuilding and secured to boundaries with $1.8 \mathrm{~m}$ high concrete block masonry boundary wall with access via a steel sliding gate. It is registered in the Deeds


property is endorsed with a mortgage bond in favour of a financial institution. The property measures 393 square metres in total extent. It is zoned for residential use. The neighbourhood is developed with a mixture of low, medium and high cost privately built houses. It is approximately less than three kilometres from the City Centre of Gaborone/CBD.

Location: The property is located in Gaborone West Block 3 (Extension 30) low cost area along Boragane Crescent branching off Buishivango Raod in close proximity to amenities and infrastructural services. Spar Supermarket, Khama Community Junior Secondary School, Hillcrest English Medium School, Ithumeleng Primary School, FNB Bank, Travel and Planet Lodges are all in close proximity to the subject property. In Botswana, the most popular type of housing development is integrated housing which is a mixture of low, medium and high cost areas within one location.

Construction details: The main house is constructed from a hipped concrete tiled roof on timber trusses/battens with rhino board ceiling over solid concrete stock brick masonry walls, glazed ceramic wall tiles to wet areas up to ceiling level, plastered, rendered and painted internally and externally. Aluminium glazed framed windows. Steel door frames incorporating steel plated doors internally to external entrances. Timber door frames incorporating hollow core flush doors. Solid reinforced concrete floor slab cement/sand screeded and overlaid with porcelain tiles.

The outbuilding is constructed from a mono pitched IBR roof on timber rafters/purlins without ceiling over hollow concrete block masonry walls, plastered, rendered and painted internally and plastered, rendered and rough casted externally. Steel framed glazed windows with burglar bars, Pressed steel door frames incorporating solid FLB Match boarded doors to external entrances and security door to verandah opening. Solid reinforced concrete floor slab cement/sand screeded to a smooth finish.

Accommodation: The main house comprises an entrance verandah, open plan lounge cum dining, kitchen with base and wall units with granite work tops together with electrical appliances and fittings, passage way, common bathroom with Jacuzzi, shower, water closet and vanity basin, two bedrooms with built-in cupboards and master bedroom with built-in cupboards and an ensuite bathroom with Jacuzzi, shower, water closet and vanity basin.

The outbuilding comprises an entrance verandah, lounge, kitchen with stainless steel sink unit, bathroom with shower, water closet and wash hand basin and one bedroom (not fitted).

Approximate Total External Plinth Areas

Main house $134.50 \mathrm{M}^{2}$

Outbuilding $35.67 \mathrm{~m}^{2}$

Condition: The buildings were in a good state of repair and decoration and the main house was newly built with modern fittings and finishes.

Valuation: Using the direct comparison method, the open market value of the subject property was valued at the time of undertaking this study at P900,000.00(Nine Hundred Thousand Pula Only).

Monthly Instalment: The monthly instalment for this property would be around P7,527.96 per month. This was computed using a financial calculator/excel. The following parameters were input in the calculator/excel. Principal amount $(P V)=-900,000 ; I=$ interest rate @ 8\% per annum/12months; $n=$ number of years $20 \star 12$ months = 240; compute monthly payment $(P M T)=P 7,527.96$. This instalment according to the banks should not exceed 30 percent of one's income which is in line with what the UN Habitat recommends.

These parameters were used to segment the property markets and finally the target market was identified based on the attributes discussed in the results. Respondents were then asked if they would like to buy a house with the above mentioned attributes. 


\section{Literature Review}

A target market is defined as a set of buyers sharing common needs/characteristics that the company decides to serve (Kotler, 2012). The marketing literature identifies segmentation process as STP marketing (Kotler, 1998) while Kumar (2010) affirms that the three steps in the segmentation process are known together as the STP strategy/principle. Kumar (2010) further stresses that the STP strategy/principle can be defined as the process of segmenting the market, targeting the most atractive markets and positioning the firm's product to the market segments.

The target market identification is based on the premise that one need to establish what they ought to satisfy in order for consumers to be attracted to the product offering. This then takes the form of identification of needs satisfaction in property marketing (The National Property Education Committe, 1996:7-9). Need satisfaction can take any of the following forms:

1. Establishing what exactly the target customers will be looking for in terms of locality, size, amenities, finishes as well as the image of a property at different price/rental levels.

2. Selecting the locality for erecting a building for housing.

3. Designing, constructing and finishing a housing unit with the view of selling, letting or occupying it.

4. Matching customer requirements for housing with potentially available properties through estate agency functions. This implies the selection of properties, matching of needs and closing of transactions.

5. After purchase satisfaction implying that customer's experiences joy and happiness in occupying the property purchased.

6. Matching customers' needs with potential available properties.

7. Repeat purchases establish the success of delivering need satisfaction projects and services by the property marketer would be repeat purchases by existing clients from previous transactions.

From the above discussion, it is clear that marketing acts as a filter working in two directions trying to (one) ascertain needs of customers and (two) making sure these needs are met. Figures 1 and 2 are an illustration of the two marketing tasks being assessment of customers' needs and satisfying the customer's needs. These are fulfilled by developing a marketing program comprising the four variables of marketing mix elements namely, product, price, promotion and place.
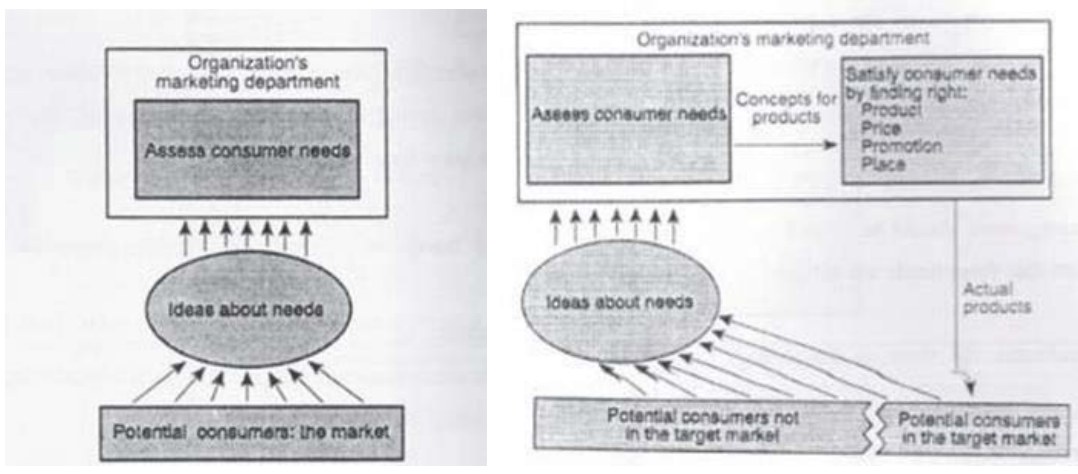

Figure 1: Assess customer needs

Figure 2: Satisfy customer needs (Berkowitz, Kerin, \& Rudelius, 1989)

The first step is to segment the market. Kumar (2010) defines market segmentation as the process of grouping buyers common desires and needs into different categories while Cravens (1997), Peter \& Olson (1996) says it is a process of placing the buyers in a product-market into subgroups so that the buyers in a segment display similar responsiveness to a particular positioning strategy. On other hand Kotler (2012), Levitt (1983), Wood (2004) state that it involves dividing a market into smaller segments of buyers with distinct needs/characteristics or behaviours that might require separate marketing startegies or mixes.

Market segmentation, targeting and positioning are achieved through a six step evaluation as highlighted in the figure below: 


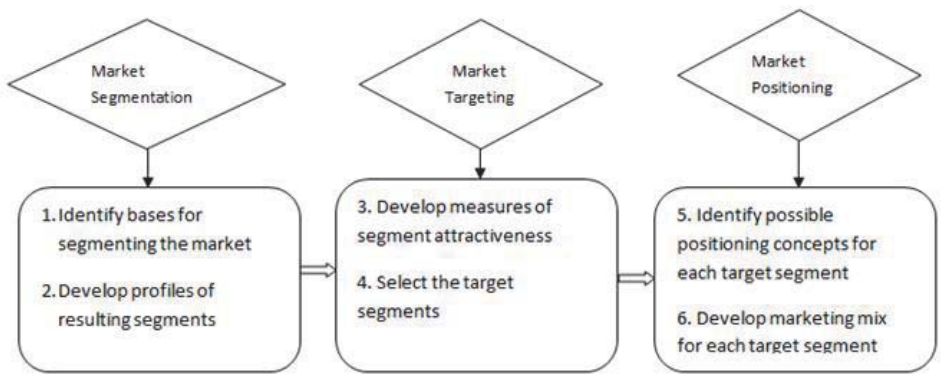

Figure 3: Six steps of evaluating STP

Adapted from (Kotler, Wong, Saunders, \& Armstrong, 2005)

Kotler, Wong, Saunders, \& Armstrong (2005) outline the following as major variables used in segmenting consumer markets. These are:

- Geographic segmentation which divides the market into different geographical units such as cities or neighbourhoods.

- Demographic segmentation which divides markets into groups based on demographic variables such as age, sex, household size, family life cycle, income, occupation, education, religion, race and nationality. These are the most used factors bases for segmenting different consumer groups since they are easily measured than most of the other form of variables.

- Psychographic segmentation divides buyers into groups based on their social class, lifestyle or personality characteristics. These make- ups always vary even when consumers fall in the same geographic group.

- Behavioural segmentation which divides buyers into groups based on their knowledge, attitudes, use or response to a product. The majority of marketers have identified behaviour variables to be an effective way to construct market segments.

Siong (1994) suggests that in real estate, demand for housing can be divided/grouped by housing category (low, medium and high cost), ethnicity (e.g. Chinese, Indian) and zones (distance from the city).

Kotler et al (2005) further states that effective market segments should have the following characteristics:

- Measurability: The degree to which the size, purchasing power and profits of a market segment can be achieved.

- Accessibility: The degree to which a market segment can be reached and served.

- Sustainability: The sufficeince and profitability of the market segment.

- Actionability: The degree to which effective marketing programmes can be designed for attracting and serving a given market.

The National Property Education Committe (1996) has identified requirements for a market to be termed a target market. These are:

- People: sufficient numbers of people justisfy the creation of a market.

- People with desires: people themselves does not constitute a market. A desire should exist to purchase and use a specific product.

- People with buying power: people should have enough buying power to satisfy the desire for the product.

- People who are willing to buy: people should show willingness to give up money in exchange for need satisfying attributes offered by the marketing firm.

- People with eligibility to buy: people should be legally and morally eligible to buy a specific product.

- People who are most attracted to the marketing firm's offerings: a target market comes into being when a marketing firm effectively matches its offering to specific needs and desires of a specific target group.

Product positioning is arranging for a product to occupy clear, distinctive and desirable place relative to competing products in the minds of the target consumers. It may also mean setting the competitive positioning for the product and creating a detailed marketing mix (Kotler et al, 2005). Positioning is usually done after both segmentation and targeting have been done, the target group would have been identified through its potential profitability. Cravens (1997) defines positioning as the combination of various marketing actions to meet needs and wants of each target. This strategy consists of product and support services, distribution, pricing and promotion activities in different segments. With 
reference to step one in figure 3, Kotler et al (2005) highlights that the first step in the positioning process is to develop positions for each segment. This includes ways of giving the product an advantage over others such as low costs and high quality finish to influence the target consumers to position in the product and address perceptions, impressions and feelings that consumesr hold for the product in comparison with competing products.

According to Schoel (1985) positioning strategies consist of the following three steps:

- Identifying potential competitive advantages.

- Selecting the competitive advantage.

- Communicating the competitive advantage.

On the other hand Kotler et al (2005) have highlighted the strategies for positioning as follows:

- Product attribute: The strategy position for the product according to its competitive and desirable attributes.

- Benefits offered: this one addresses the need that consumers want. The strategy highlights those needs against other products in the market to position the product to targeted consumers.

- Unique selling proposition: a situation whereby the unique product benefits that a marketer aggressively promotes in a consistent manner to its target market. The benefits usually reflects functional superiority, best quality, best services, low prices and most advanced technology.

The final stage (figure 3) is developing a marketing mix. Kotler et al (2005) defines marketing mix as the set of controllable tactical marketing tools that organisations blends to produce the response it wants in the target market. The marketing mix are product, place, price and promotion. It is the blend of these elements that makes up a marketing mix.

\section{Methodology}

Both non-probability and probability sampling techniques were used by applying qualitative and quantitative research methods (interviews and questionnaire) to get research data in order to meet the objective of the study. The population of 250 was identified and a sample size of 152 was determined based on the criteria for establishing the sample size in table 1 at 95\% confidence level (Leedy, 1997).

Table 1: Sample sizes $(\mathrm{S})$ required for a given population size

\begin{tabular}{|cc|cc|cc|cc|cc|}
\hline$N$ & $S$ & $N$ & $S$ & $N$ & $S$ & $N$ & $S$ & $N$ & $S$ \\
\hline 10 & 10 & 100 & 80 & 280 & 162 & 800 & 260 & 2800 & 338 \\
15 & 14 & 110 & 86 & 290 & 165 & 850 & 265 & 3000 & 341 \\
20 & 19 & 120 & 92 & 300 & 169 & 900 & 269 & 3500 & 346 \\
25 & 24 & 130 & 97 & 320 & 175 & 950 & 274 & 4000 & 351 \\
30 & 28 & 140 & 103 & 340 & 181 & 1000 & 278 & 4500 & 354 \\
35 & 32 & 150 & 108 & 360 & 186 & 1100 & 285 & 5000 & 357 \\
40 & 36 & 160 & 113 & 360 & 191 & 1200 & 291 & 6000 & 361 \\
45 & 40 & 170 & 118 & 400 & 196 & 1300 & 297 & 7000 & 364 \\
50 & 44 & 180 & 123 & 420 & 201 & 1400 & 302 & 8000 & 367 \\
55 & 48 & 190 & 127 & 440 & 2015 & 1500 & 306 & 9000 & 368 \\
60 & 52 & 200 & 132 & 460 & 210 & 1600 & 310 & 10000 & 370 \\
65 & 56 & 210 & 136 & 480 & 214 & 1700 & 313 & 15000 & 375 \\
70 & 59 & 220 & 140 & 500 & 217 & 1800 & 317 & 20000 & 377 \\
75 & 63 & 230 & 144 & 550 & 226 & 1900 & 320 & 30000 & 379 \\
80 & 66 & 240 & 148 & 600 & 234 & 2000 & 322 & 40000 & 380 \\
85 & 70 & 250 & 152 & 650 & 242 & 2200 & 327 & 50000 & 381 \\
90 & 73 & 260 & 155 & 700 & 248 & 2400 & 331 & 75000 & 382 \\
95 & 76 & 270 & 159 & 750 & 254 & 2600 & 335 & 100000 & 384 \\
\hline
\end{tabular}

A survey instrument using a guide questionnaire was developed and administered to 152 respondents who were working and earning a monthly salary in order to meet the minimum qualifying criteria for a home loan being $30 \%$ of one's income to service mortgage payments. 85 respondents returned the filled questionnaires translating to 56 percent response rate. The reason for use of the questionnaire was to try and find answers to the research questions raised. The study was confined to Gaborone the capital city of Botswana because it was the most convenient location for the researcher. The selection of a sample size was done using a systematic random sampling. 
Table 2: HIE 2002/03: Distribution of household income, strata and sex of head (Statistics Botswana, 2010).

\begin{tabular}{|c|c|c|c|c|c|c|c|c|c|c|c|c|c|c|c|c|}
\hline \multirow[b]{2}{*}{ Noptens } & \multicolumn{3}{|c|}{ Natebs } & \multicolumn{4}{|c|}{ onvtas } & \multicolumn{5}{|c|}{ tous velugs } & \multicolumn{4}{|c|}{ Ratatine } \\
\hline & $\mathrm{Cen}$ & Tuen & Mot & Fetse & an & Tat & $\mathrm{Mt}$ & Fenet & $\mathrm{cm}$ & toen & Not & fetsit & Oan & Tual & $\mathrm{Mtak}$ & Pent \\
\hline din & 2 & 2 & 23 & 19 & 13 & 13 & 12 & 15 & 17 & 17 & 14 & 21 & 27 & 27 & 38 & 14 \\
\hline $16: 20$ & 49 & 28 & 26 & 31 & 23 & 1 & es & 13 & 37 & 2 & 12 & 27 & 74 & 47 & 48 & 43 \\
\hline 2030 & 91 & d] & 34 & 33 & 13 & 12 & 07 & 19 & 16 & 39 & 3 & 47 & 14 & 66 & 57 & 21 \\
\hline twan & 147 & 56 & 42 & 72 & 56 & 21 & 1 & 31 & 127 & $\$ 1$ & 32 & 69 & 223 & $\mathbf{N}$ & 73 & 94 \\
\hline anson & 212 & 63 & 6 & 71 & 97 & 41 & 31 & 56 & 183 & 56 & 54 & $\$ 8$ & 3 & 87 & 85 & 9 \\
\hline $\sin 83$ & 从9 & 138 & w1 & 145 & 195 & 98 & 86 & 113 & 285 & 102 & 89 & 113 & 501 & 192 & 192 & 191 \\
\hline 786109 & 451 & tos & 44 & 125 & 3: & 17 & 32 & 95 & kI & 106 & 79 & $\mathrm{~b}$ & 626 & 125 & 113 & 18s \\
\hline $106415 n$ & 593 & ns & 124 & 14 & 419 & 118 & BI & us & 526 & as & 107 & 161 & 759 & 133 & 13 & us \\
\hline 15w:200 & 631 & 15 & 92 & 76 & 51 & 91 & 93 & 89 & 81 & 96 & 112 & 81 & $\mathbf{n 2}$ & 73 & 79 & 66 \\
\hline 296469 & $n 3$ & 95 & 10 & 9 & 621 & 121 & 121 & 12 & 742 & 121 & is & 94 & $m 2$ & 6 & 52 & 69 \\
\hline 3046 & $\mu$ & 67 & 72 & 62 & 716 & s.5 & 91 & 79 & 26 & 84 & 97 & 73 & 914 & 43 & 42 & 4 \\
\hline mo เ⿻ & ns & 65 & 73 & 3 & 112 & 96 & 98 & 93 & 906 & 1 & 10.1 & 6.1 & $\$ .7$ & 32 & 46 & 16 \\
\hline 604860 & 941 & 16 & 4 & 11 & 173 & 61 & 61 & 6 & $\$ 46$ & 4 & 43 & 35 & (4) & 17 & 23 & 69 \\
\hline  & $\$ 2$ & 21 & 23 & 12 & 91 & 38 & 5 & 2 & 9.1 & 25 & 36 & 15 & 98 & 66 & 67 & es \\
\hline 1606-1509 & w2 & $M$ & 43 & 16 & 97s & 6? & 88 & 36 & 96 & 25 & 16 & 14 & 106 & 1 & 15 & 65 \\
\hline BNont & 100 & as & 13 & 02 & 190 & 22 & 32 & 66 & $\mathbf{m}$ & e4 & et & 01 & 100 & 0 & el & 9 \\
\hline Total & & 100 & 100 & 100 & & 10 & 100 & 10 & & 100 & 100 & 100 & & 100 & 100 & 100 \\
\hline Tolal austert & & man & 211,233 & $18 x 9$ & & 100.546 & $657 x$ & ans & & 213: & $57 \times 80$ & 6142 & & $1613 x$ & 50,793 & 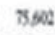 \\
\hline $\mathbf{m i n}$ & & 24461 & 2918.14 & Lesu on & & 1961.11 & 26538 & 236214 & & 24054 & $29 A 1 D$ & 1962 12 & & 10893 & $1851 \%$ & 177822 \\
\hline L19 & & 35812 & $609 x$ & 31951 & & 540 & 600 & socese & & W6s & 4123 &  & & $2 A \mathrm{~L}$ & 2007 & 8176 \\
\hline LS & & 6415 & 733.45 & 5005 & & $\sin$ & $\cos 8$ & 712 & & 6504 & $\pi 50$ & 3564 & & 4176 & 41525 & 4561 \\
\hline Medus & & 1,4410 & $15 \% 05$ & $\tan 9$ & & 1,495 & $2 \ln \omega$ & $1500 \times 3$ & & Lass & 184445 & 10564 & & $73 \times 8$ & $x 353$ & mas: \\
\hline 195 & & 3254 & 150083 & 250110 & & $465 x$ & 500.11 & 187270 & & 291285 & 3552 & 2.1020 & & 14228 & 15576 & 1,100 \\
\hline 10 & & 7908 & 2,759 & $5.112 \mathrm{~K}$ & & 96478 & 1160020 & 681466 & & $50 x=0$ & 6514.42 & 4543 & & 1) & 18559 & 25ns: \\
\hline
\end{tabular}



The numeric data was analysed statistically using Microsoft Excel.

\section{Findings}

In order to identify the target market for a proposed housing development using the principle of market segmentation, targeting and product position strategy, the following research objectives were developed to help address the research problem. These were as follows:

a) To identify the target market that can afford to purchase the proposed development and are attracted to the product that is being offered on the market.

b) To establish if there is demand for the proposed house development.

c) To segment the markets for the proposed development into various categories.

d) To evaluate the response obtained from the market on the proposed development.

A questionnaire was developed containing information that was used to address and achieve the objectives of the study. The responses from the respondents were as follows:

1. The first part of the questionnaire was about the demographic profile of the respondents which helped the researcher to establish the segments that will be investigated further.

2. The respondents were asked to indicate on the questionnaire their sex and the age range. The responses were as tabulated in the figure below. 


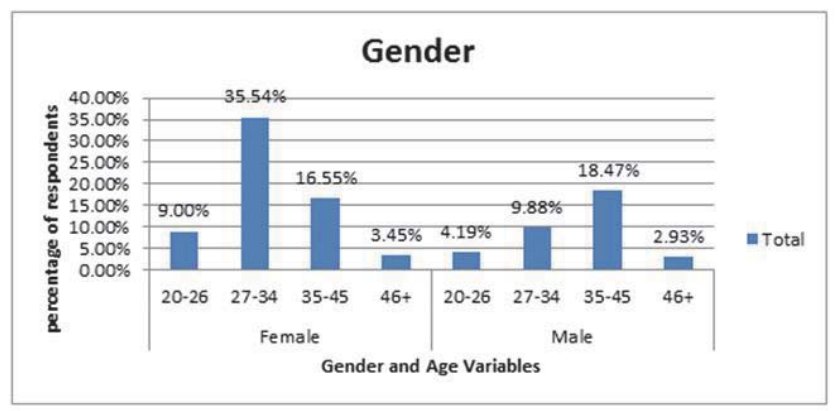

Figure 4: Gender of respondents

The gender composition of the respondents was 64.54 percent for females and 35.46 percent for males. Out of the 64.54 percent for the female respondents, 9.00 percent were between the ages of 20 to 26 years, 35.54 percent were between 27 to 34 years, 16.55 percent were between $35-45$ years and 3.45 percent were above 46 years. Out of the 35.46 percent for the male respondents, 4.19 percent were between 20 to 26 percent, 9.88 percent were between 27 to 34 years, 18.47 percent were between to 35 to 45 years, and 2.93 percent were above 46 years as illustrated in figure 4 and table 3 . Based on the combined age and gender 81.18 percent of the respondents were deemed to fall within the most attractive segments. From the results above based on gender, the following age groups were not considered as they are less attractive as indicated in table 3 below.

Table 3: Gender and Age of Respondents

\begin{tabular}{ccc} 
DESCRIPTION & FREQUENCY & COMMENTS \\
\hline Female & $\mathbf{6 4 . 5 4 \%}$ & \\
\hline $20-26$ & $9.00 \%$ & Less attractive segment \\
$27-34$ & $35.54 \%$ & Most attractive Segment \\
$35-45$ & $16.55 \%$ & Most attractive Segment \\
$46+$ & $3.45 \%$ & Less attractive Segment \\
Male & $35.46 \%$ & \\
\hline $20-26$ & $4.19 \%$ & Less attractive segment \\
$27-34$ & $9.88 \%$ & Most attractive Segment \\
$35-45$ & $18.47 \%$ & Most attractive Segment \\
$46+$ & $2.93 \%$ & Less attractive Segment \\
\hline Grand Total & $100.00 \%$ &
\end{tabular}

3. The respondents were also asked to state their occupation which is one of the segments that will be looked at further. From figure 5 below, 15.29 percent were managers from the public sector, 81.18 percent were managers/professionals from the private sector, 2.35 percent were medical Doctors and 1.18 percent were technicians. In order to establish the attractiveness of these segments, the occupation variable was then analysed together with the age variable as outlined in table 4 below. The reason was to establish which segments would be the most attractive ones taking into account the age of the respondents. From table 2 below, looking at the combined variables of occupation and age, only 81.18 percent were considered to be in the most attractive segments. The reason for rejection of the age group from 20 to 26 is that most of these could be university graduate starters and they might not have enough income to purchase a house at that price. The other age group of 46 and above will not be economically active after the compulsory retirement age of 55 in Botswana, therefore they might still be owing and end up using pension benefits to clear the outstanding balance for the remaining term of 20 years. The overall score for most attractive segments was 81.18 percent. 


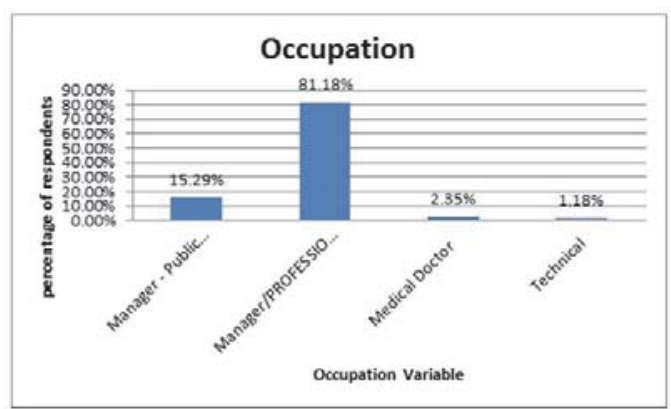

Figure 5: Occupation of respondents

In table 4 below it is clear that managers in the public sector between the age groups of 27-34 and 35 to 45 will be the most attractive segments with a combined percentage score of 11.76 , the private sector managers/professionals are also the most attractive segments with a percentage score of 67.06 , the Medical Doctors in the age group of 35 to 45 with a percentage score of 1.18 and the technician in the age group of 27 to 34 with a 1.18 percent.

Table 4: Age and Occupation of respondents

\begin{tabular}{ccc} 
Description & FREQUENCY & COMMENTS \\
\hline Manager - Public Sector & $15.29 \%$ & \\
\hline $20-26$ & $3.53 \%$ & Less attractive Segment \\
$27-34$ & $2.35 \%$ & Most attractive Segment \\
$35-45$ & $9.41 \%$ & Most attractive Segment \\
\hline Manager/PROFESSIONAL/- Private Sector & $81.18 \%$ & \\
\hline $20-26$ & $9.41 \%$ & Less attractive segment \\
$27-34$ & $38.82 \%$ & Most attractive Segment \\
$35-45$ & $28.24 \%$ & Most attractive Segment \\
$46+$ & $4.71 \%$ & Less attractive segment \\
Medical Doctor & $2.35 \%$ & \\
\hline $35-45$ & $1.18 \%$ & Most attractive Segment \\
$46+$ & $1.18 \%$ & Less attractive segment \\
\hline Technical & $1.18 \%$ & \\
\hline 27-34 & $1.18 \%$ & Most attractive Segment \\
\hline Grand Total & $100.00 \%$ &
\end{tabular}

4. The respondents were asked to indicate their level of education on the questionnaire, the results in figure 6 below show that amongst them 63.53 percent were degree holders, 8.24 percent were diploma holders, 15.29 percent were master's degree holders, 8.24 percent were holders of other certificates and 4.71 percent were PhD holders.

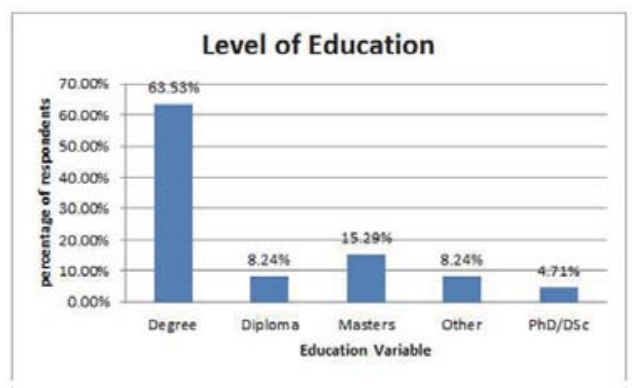

Figure 6: Qualifications variable. 
The table below was further combined with the age variable in order to establish the most attractive segments. Out of 63.53 percent for degree holders, only 50.59 percent were most attractive, out of 8.24 percent diploma holders, 7.06 were considered to be in most attractive segment, out of 15.29 percent master's degree holders, 12.94 percent were considered to be in the most attractive segment based on the age segment, out of 8.24 percent holders of other certificates, only 5.88 percent were in the most attractive segment and 4.71 percent $\mathrm{PhD}$ holders were all in the most attractive segment. The overall score for most attractive segments was 81.18 percent.

Table 5: Combined Education and Age variables.

\begin{tabular}{ccc} 
DESCRIPTION & FREQUENCY & COMMENTS \\
\hline Degree & $63.53 \%$ & Less attractive Segment \\
\hline $20-26$ & $9.41 \%$ & Most attractive Segment \\
$27-34$ & $27.06 \%$ & Most attractive Segment \\
$35-45$ & $23.53 \%$ & Less attractive Segment \\
$46+$ & $3.53 \%$ & \\
Diploma & $8.24 \%$ & Less attractive Segment \\
\hline $20-26$ & $1.18 \%$ & Most attractive Segment \\
$27-34$ & $5.88 \%$ & Most attractive Segment \\
$35-45$ & $1.18 \%$ & Most attractive Segment \\
Masters & $15.29 \%$ & Most attractive Segment \\
$27-34$ & $5.88 \%$ & Less attractive Segment \\
$35-45$ & $7.06 \%$ & \\
$46+$ & $2.35 \%$ & Less attractive Segment \\
Other & $8.24 \%$ & Most attractive Segment \\
\hline $20-26$ & $2.35 \%$ & Most attractive Segment \\
$27-34$ & $2.35 \%$ & \\
$35-45$ & $3.53 \%$ & Most attractive Segment \\
PhD/DSc & $4.71 \%$ & Most attractive Segment \\
\hline $27-34$ & $1.18 \%$ & \\
\hline $35-45$ & $3.53 \%$ &
\end{tabular}

5. The respondents were asked to indicate their marital status as shown in figure 7 below, 2.35 percent were divorced, 57.65 percent were married, 38.82 percent were single and 1.18 percent were widowed and was above 46 years



Figure 7: Qualifications variable.

Table 6 below was generated from the above results to categorise the segments into less and most attractive segments. 2.35 percent divorced respondents were within the most attractive segment, while out of 57.65 percent of married respondents, only 48.24 were considered to be in the most attractive segments and out of 38.82 percent single respondents, only 30.59 percent were in the most attractive segment. The overall score for most attractive segments was 81.18 percent. 
Table 6: Combined variables marital status and age

\begin{tabular}{ccc} 
Description & Frequency & COMMENTS \\
\hline Divorced & $2.35 \%$ & Most attractive Segment \\
\hline $27-34$ & $1.18 \%$ & Most attractive Segment \\
$35-45$ & $1.18 \%$ & \\
Married & $57.65 \%$ & Less attractive Segment \\
\hline $20-26$ & $4.71 \%$ & Most attractive Segment \\
$27-34$ & $22.35 \%$ & Lost attractive Segment \\
$35-45$ & $25.88 \%$ & \\
$46+$ & $4.71 \%$ & Less attractive Segment \\
Single & $38.82 \%$ & Most attractive Segment \\
\hline $20-26$ & $8.24 \%$ & Most attractive Segment \\
$27-34$ & $18.82 \%$ & Less attractive Segment \\
$35-45$ & $11.76 \%$ & $\mathbf{1 0 0 . 0 0 \%}$
\end{tabular}

6. The respondents were asked to indicate the household size on the questionnaire, from the results in figure 8 below, 35.65 percent were respondents with a family size of 1 to $2,57.65$ percent with a family size of 3 to 4 and 4.71 with a family size of 5 to 6 . Table 7 was generated to establish which segments would be most attractive after combining the two variables age and household size.

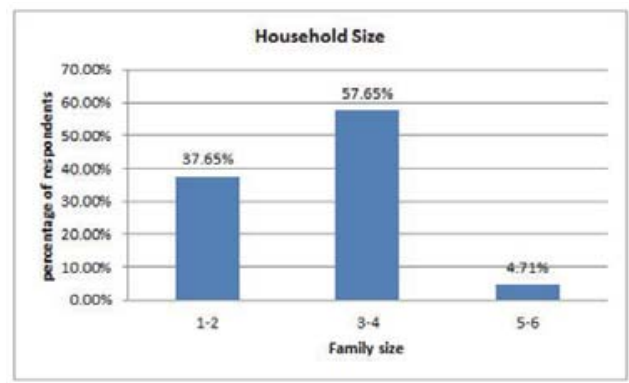

Figure 8: household size and age

From table 7 below, out of 37.65 respondents with the household size of 1 to 2, only 28.24 percent were in the most attractive segment, out of 57.65 percent of respondents with a household size of 3 to 4 , only 49.41 percent were within the most attractive segment, and out of 4.71 percent of respondents with a household size of 5 to 6 , only 3.53 were within the most attractive segment. The overall score for the most attractive segments was 81.18 percent.

Table 7: combine variables household size and age

\begin{tabular}{ccc} 
DESCRIPTION & FREQUENCY & COMMENTS \\
\hline $\mathbf{1 - 2}$ & $37.65 \%$ & Less attractive Segment \\
$20-26$ & $7.06 \%$ & Most attractive Segment \\
$27-34$ & $18.82 \%$ & Most attractive Segment \\
$35-45$ & $9.41 \%$ & Less attractive Segment \\
$46+$ & $2.35 \%$ & \\
$3-4$ & $57.65 \%$ & Less attractive Segment \\
$20-26$ & $5.88 \%$ & Most attractive Segment \\
$27-34$ & $22.35 \%$ & Lest attractive Segment \\
$35-45$ & $27.06 \%$ & \\
$46+$ & $2.35 \%$ & Most attractive Segment \\
$5-6$ & $4.71 \%$ & Most attractive Segment \\
\hline $27-34$ & $1.18 \%$ & Less attractive Segment \\
$35-45$ & $2.35 \%$ & \\
$46+$ & $1.18 \%$ &
\end{tabular}


7. 5.1.6 The respondents were asked to indicate which mode of transport they used when going to work. 97.65 percent of the respondents used their own cars and only 2.35 percent used public transport.

8. 5.1.7 The respondents were asked to indicate the monthly salary on the questionnaire. From figure 9 below, 30.59 percent were getting a monthly salary between $\mathrm{P} 5,000.00$ to $\mathrm{P} 10,000.00,17.65$ were earning between $\mathrm{P} 10,000.01$ up to $\mathrm{P} 15,000.00,10.59$ percent were getting between $\mathrm{P} 15,001.00$ up to $\mathrm{P} 20,000.00,18.82$ percent were getting between $\mathrm{P} 20,001.00$ up to $\mathrm{P} 25,000.00$ and 22.35 percent were getting above $\mathrm{P} 25,000.00$.

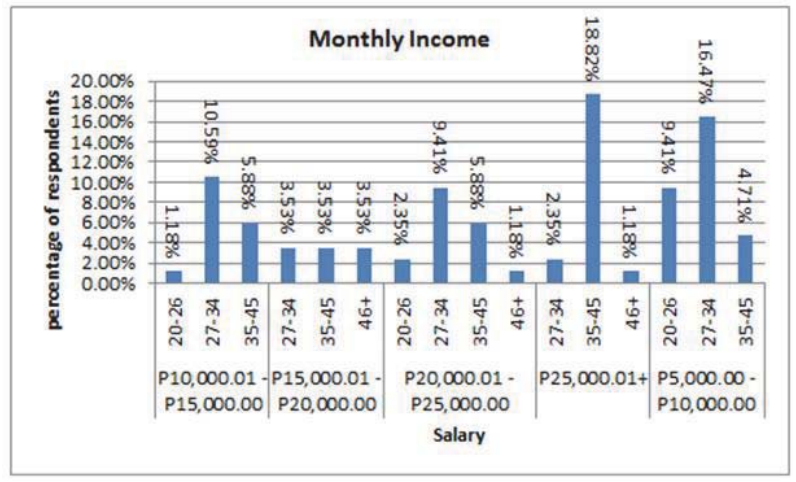

Figure 9: Monthly Income

These figures were further analysed by combining the age and income variable so that the most attractive segment could be established. From the $30 \%$ requirement as being a monthly instalment for a mortgage loan, it means for someone to qualify for a monthly instalment of $P 7,527.97$ they should be getting a monthly salary of $P 25,000.00$ and above. This criterion was used to evaluate the segments in table 8 below. From the table below it is clear that the most attractive segment is the one with a monthly income of $\mathrm{P} 25,000.00$ and above with a score of 21.18 percent out of 22.35 percent and the slightly attractive segment of 16.47 percent out of 18.82 percent. The overall score for the most attractive segments is 21.18 percent.

Table 8: combined variables income and age.

\begin{tabular}{ccc}
\hline DESCRIPTION & FREQUENCY & COMMENTS \\
\hline P10,000.01 -P15,000.00 & $17.65 \%$ & Less attractive Segment \\
\hline $20-26$ & $1.18 \%$ & Less attractive Segment \\
$27-34$ & $10.59 \%$ & Less attractive Segment \\
$35-45$ & $5.88 \%$ & Less attractive Segment \\
\hline P15,000.01 -P20,000.00 & $10.59 \%$ & Less attractive Segment \\
$27-34$ & $3.53 \%$ & Less attractive Segment \\
$35-45$ & $3.53 \%$ & Less attractive Segment \\
$46+$ & $3.53 \%$ & \\
\hline P20,000.01 -P25,000.00 & $18.82 \%$ & Slightly attractive segment \\
$20-26$ & $2.35 \%$ & Slightly attractive segment \\
$27-34$ & $9.41 \%$ & Slightly attractive segment \\
$35-45$ & $5.88 \%$ & Less attractive Segment \\
$46+$ & $1.18 \%$ & \\
\hline P25,000.01+ & $22.35 \%$ & Most attractive Segment \\
\hline $27-34$ & $2.35 \%$ & Most attractive segment \\
$35-45$ & $18.82 \%$ & Less attractive Segment \\
$46+$ & $1.18 \%$ & \\
\hline P5,000.00 -P10,000.00 & $30.59 \%$ & Less attractive Segment \\
\hline $20-26$ & $9.41 \%$ & Less attractive Segment \\
$27-34$ & $16.47 \%$ & Less attractive Segment \\
$35-45$ & $4.71 \%$ & \\
\hline Grand Total & $100.00 \%$ & \\
& & \\
\hline & $0 \bullet$ & \\
\hline
\end{tabular}


9. The respondents were asked to rate their financial status, from figure 10 below 44.71 percent of the respondents indicated that there were above average, while 29.41 percent were average and 25.88 were below average.

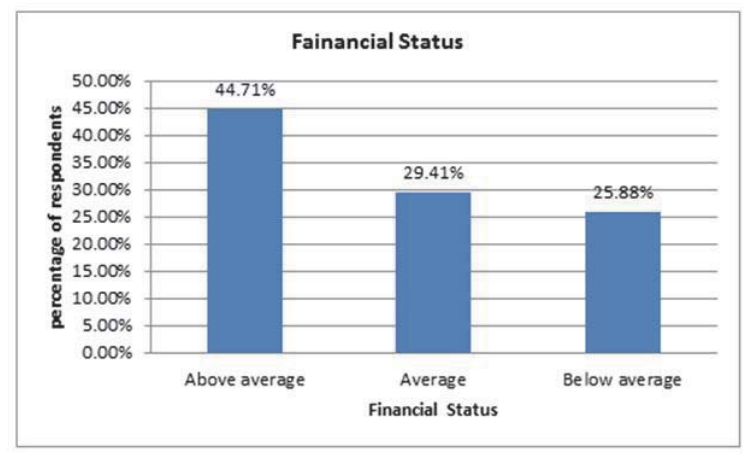

Figure 10: Financial Status.

10. Respondents were asked to rate their area of residence, from the responses 77.65 percent rated their area as urban and 22.35 percent as rural. This implies that the latter are staying in the neighbouring villages.

11. Respondents were asked to indicate their status of their housing in the questionnaire. 61.18 percent indicated that they were renting the house where as 38.82 percent were owners of the houses they were occupying. Of those who were renting, they were asked to further indicate the rent that they were paying. 40.00 percent out of 61.18 percent were paying rent between $\mathrm{P} 1,000.00$ to $\mathrm{P} 5,000.00$ and 21.18 percent were paying between $P 5,001.00$ to $P 7,000.00$. These who were paying a rental of between P5,001.00 to P7,000.00 had an overall score for the most attractive segments of 21.18 percent. Those who had bought a house were asked to indicate the instalment that they were paying. Out of the 38.82 owner occupiers, 22.35 percent were paying a monthly instalment between $\mathrm{P} 1,000.00$ to $\mathrm{P} 5,001.00$ and 16.47 percent were paying between $\mathrm{P} 7,001$ to P9,500.00 per month.

12. Respondents were asked to indicate their location on the questionnaire. From the results of the respondents, 37.65 percent were staying in Kgale View/Blocks 3,5,6,7,8, 9, \& 10 while 24.71 percent were staying in nearby Villages, 4.71 were staying in Phakalane, and 12.94 percent were staying in Phase I, II \& IV. The respondents were further asked to indicate the attributes that they liked about their neighbourhood. From the results of the respondents, 97.65 percent said they liked their neighbourhood because it was private, secure and quiet and 2.35 percent said their neighbourhood was not quiet but secure. They were further asked to rate the houses in Gaborone. 70.59 percent rated the houses as average, 2.35 percent as excellent and 27.06 percent as good. They were further asked if they would consider purchasing a house in Gaborone. 92.94 percent of the respondents were willing (positive attitude) to purchase a house in Gaborone and 7.06 percent were not willing (negative attitude) to purchase a house in Gaborone.

13. Respondents were asked to state if they were interested in buying the house and indicate how much would they offer. The results of the respondents were that 1.18 percent would offer $\mathrm{P} 1,000,001$ to $\mathrm{P} 1,100,000.00$, 3.53 percent would offer $\mathrm{P} 1,100,001$ to $\mathrm{P} 1,200,000.00,1.18$ percent would offer $\mathrm{P} 1,200,001.00$ and above, 62.35 percent would offer P800,000.00 to P900,000.00 and 31.76 would offer P900,001 to P1,000,000.00. 37.65 percent of the respondents based on the offer will be considered as the most attractive segment and 62.35 percent of the respondents will be the less attractive segment. 


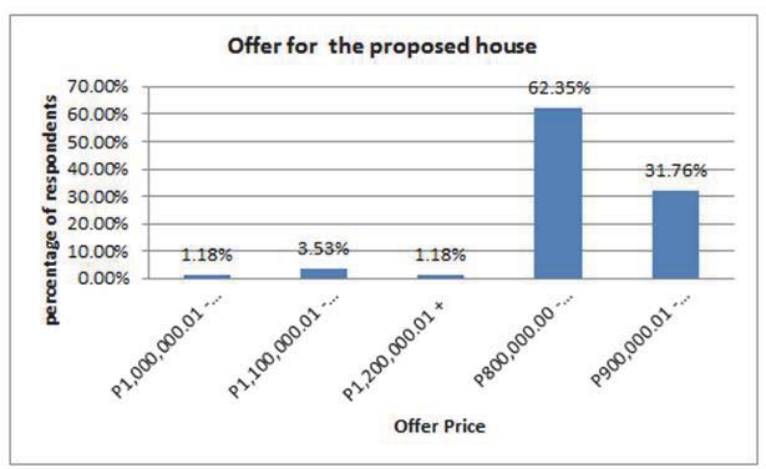

Figure 11: Offer of the proposed house.

These were further analysed using the offer, income and age variables to determine the segment which will be the most attractive. From table 9 below only 16.47 percent out of 37.65 percent of the respondents will be the most attractive segment based on the income, offer and age. This will then be the target market for this property because they are willing and are able and capable of paying for the product. 20 percent of the respondents are in a slightly attractive segment but they have to increase their offer because they are between P800,000.00 to P900,000.00. The target market in this case will be these two segments based on income, offer and age variables. Using the segmentation process one is able to identify the target market depending on the variable that is most feasible and profitable. The respondents were further asked to indicate the type of house they wanted to buy. 35.29 percent said they would prefer a high cost house and 64.71 percent would buy a medium cost.

Table 9: Offer, monthly income and the age variables

\begin{tabular}{|c|c|c|}
\hline DESCRIPTION & FREQUENCY & \\
\hline $\mathrm{P} 1,000,000.01$ - P1,100,000.00 & $1.18 \%$ & \\
\hline$P 25,000.01+$ & $1.18 \%$ & \\
\hline $27-34$ & $1.18 \%$ & Most attractive Segment \\
\hline$P 1,100,000.01$ - P1,200,000.00 & $3.53 \%$ & \\
\hline $\mathrm{P} 25,000.01+$ & $2.35 \%$ & \\
\hline $35-45$ & $2.35 \%$ & Most attractive Segment \\
\hline$P 5,000.00-P 10,000.00$ & $1.18 \%$ & \\
\hline $20-26$ & $1.18 \%$ & Less attractive Segment \\
\hline $\mathrm{P} 1,200,000.01+$ & $1.18 \%$ & \\
\hline$P 15,000.01$-P20,000.00 & $1.18 \%$ & \\
\hline $46+$ & $1.18 \%$ & Less attractive Segment \\
\hline$P 800,000.00$ - $P 900,000.00$ & $62.35 \%$ & \\
\hline$P 10,000.01$-P15,000.00 & $12.94 \%$ & \\
\hline $20-26$ & $1.18 \%$ & Less attractive Segment \\
\hline $27-34$ & $8.24 \%$ & Less attractive Segment \\
\hline $35-45$ & $3.53 \%$ & Less attractive Segment \\
\hline$P 15,000.01-P 20,000.00$ & $4.71 \%$ & \\
\hline $35-45$ & $2.35 \%$ & Less attractive Segment \\
\hline $46+$ & $2.35 \%$ & Less attractive Segment \\
\hline$P 20,000.01-P 25,000.00$ & $15.29 \%$ & \\
\hline $20-26$ & $2.35 \%$ & Less attractive Segment \\
\hline $27-34$ & $7.06 \%$ & Slightly attractive Segment \\
\hline $35-45$ & $4.71 \%$ & Slightly attractive Segment \\
\hline $46+$ & $1.18 \%$ & Less attractive Segment \\
\hline$P 25,000.01+$ & $8.24 \%$ & \\
\hline $27-34$ & $1.18 \%$ & Slightly attractive Segment \\
\hline $35-45$ & $7.06 \%$ & Slightly attractive Segment \\
\hline
\end{tabular}




\begin{tabular}{|c|c|c|}
\hline$P 5,000.00-P 10,000.00$ & $21.18 \%$ & \\
\hline $20-26$ & $4.71 \%$ & Less attractive Segment \\
\hline $27-34$ & $15.29 \%$ & Less attractive Segment \\
\hline $35-45$ & $1.18 \%$ & Less attractive Segment \\
\hline$P 900,000.01$ - P1,000,000.00 & $31.76 \%$ & \\
\hline$P 10,000.01$-P15,000.00 & $4.71 \%$ & \\
\hline $27-34$ & $2.35 \%$ & Less attractive Segment \\
\hline $35-45$ & $2.35 \%$ & Less attractive Segment \\
\hline$P 15,000.01-P 20,000.00$ & $4.71 \%$ & \\
\hline $27-34$ & $3.53 \%$ & Less attractive Segment \\
\hline $35-45$ & $1.18 \%$ & Less attractive Segment \\
\hline$P 20,000.01-P 25,000.00$ & $3.53 \%$ & \\
\hline $27-34$ & $2.35 \%$ & Most attractive Segment \\
\hline $35-45$ & $1.18 \%$ & Most attractive Segment \\
\hline $\mathrm{P} 25,000.01+$ & $10.59 \%$ & \\
\hline $35-45$ & $9.41 \%$ & Most attractive Segment \\
\hline $46+$ & $1.18 \%$ & Less attractive Segment \\
\hline$P 5,000.00-P 10,000.00$ & $8.24 \%$ & \\
\hline $20-26$ & $3.53 \%$ & Less attractive Segment \\
\hline $27-34$ & $1.18 \%$ & Less attractive Segment \\
\hline $35-45$ & $3.53 \%$ & Less attractive Segment \\
\hline Grand Total & $100.00 \%$ & \\
\hline
\end{tabular}

Respondents were further asked to indicate the number of bedrooms that they would want to have in the proposed development. Responses are shown in figure 12 and table 10 below, 5.88 percent were looking for a 2 bedroomed house, 87.06 percent were in favour of a 3 bedroomed house and 7.06 percent wanted a 4 bedroomed house. These responses were further broken down as outlined in table 10.

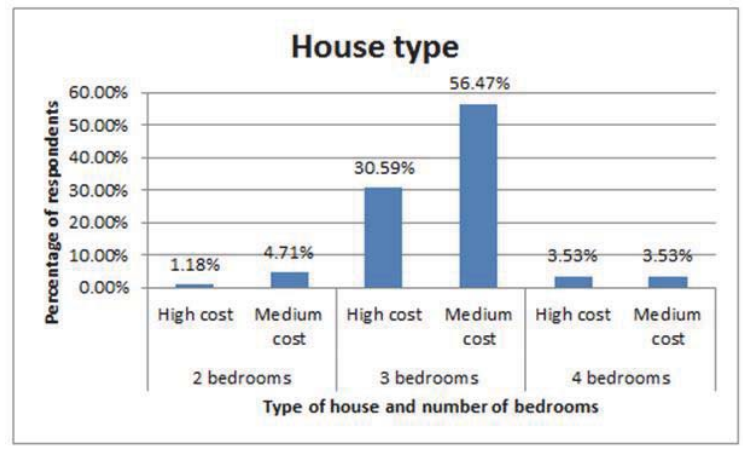

Figure 12: House type and number of bedrooms

Table 10: Combined variables house type and number of bedrooms

\begin{tabular}{cc}
\hline DESCRIPTION & FREQUENCY \\
\hline 2 bedrooms & $\mathbf{5 . 8 8 \%}$ \\
\hline High cost & $1.18 \%$ \\
Medium cost & $4.71 \%$ \\
3 bedrooms & $\mathbf{8 7 . 0 6 \%}$ \\
\hline High cost & $30.59 \%$ \\
Medium cost & $56.47 \%$ \\
4 bedrooms & $\mathbf{7 . 0 6 \%}$ \\
\hline High cost & $3.53 \%$ \\
Medium cost & $3.53 \%$ \\
\hline Grand Total & $100.00 \%$
\end{tabular}


14. The respondents were asked to indicate the distance they would like to travel from their house to work place. The responses were that 4.71 percent were in favour of 10 kilometres, 45.88 percent did not mind travelling between 5 to 9 kilometres, 48.24 percent preferred 3 to 4 kilometres and 1.18 percent were in favour of 1 to 2 kilometres. The subject property is located within three kilometres from the City Centre of Gaborone. They were further asked to indicate whether their housing needs would be met from buying a 3 bedroomed house. Results from the respondents were that 95.29 percent were satisfied with a three bedroomed house and 4.71 percent were highly satisfied. This implies that 100 percent of the respondents were satisfied with buying a 3 bedroomed house. This implies that according to their taste and preferences the three bedroomed house was a right choice for them.

Table 11: Distance between home and place of work

\begin{tabular}{ccl} 
DESCRIPTION & FREQUENCY & COMMENTS \\
\hline 10 kilometres + & $4.71 \%$ & Less attractive Segment \\
1-2 kilometres & $1.18 \%$ & Slightly attractive Segment \\
3-4 kilometres & $48.24 \%$ & Most attractive Segment \\
5-9 kilometres & $45.88 \%$ & Less attractive Segment \\
\hline Grand Total & $\mathbf{1 0 0 . 0 0 \%}$ &
\end{tabular}

15. Respondents were asked to indicate the level of satisfaction that will be achieved by having the features that would be required of the house in terms of design and finishes by indicating low satisfaction (1) up to high satisfaction (5). The chart below illustrates the results. From the results in the figure below, the level of satisfaction is fully met by having the features which are highlighted. 100 percent of the respondents felt fully satisfied if the house to be developed had the features that are shown in figure 13 below.

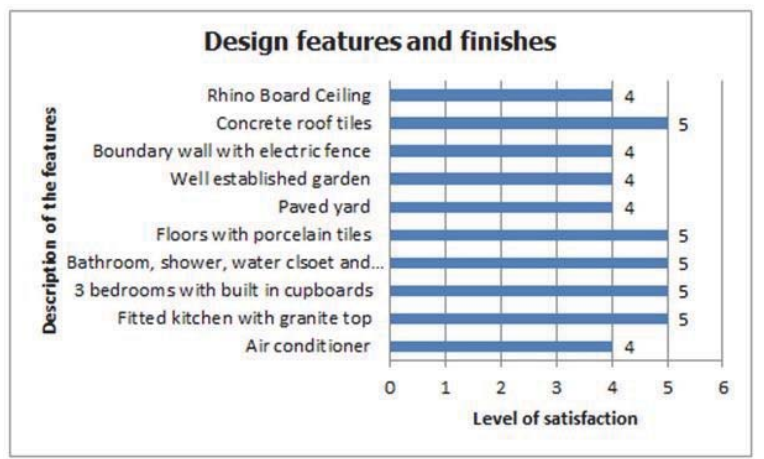

Figure 13: Design features and finishes

\section{Conclusions}

An analysis of the potential target market through the application of the STP principle/model revealed the following:

1. There are only two feasible target markets for the three bedroomed/two bathroom medium/high cost house built on a low cost plot as a result of gentrification being only $16.47 \%$ for the most attractive segment based on the income, offer and age and 20 percent of the respondents that are in a slightly attractive segment but they have to increase their offer because they are between P800,000.00 to P900,000.00 which is not far from the asking price of $\mathrm{P} 900,000.00$.

2. These two segments were identified using the four major variables used in segmenting consumer markets (Kotler et al, 2005). The major four variables that were used to segment the two target markets are Geographic segmentation, Demographic segmentation, Psychographic segmentation and Behavioural segmentation.

3. The effective market segments were identified using the following characteristics such as measurability, 
accessibility, sustainability and actionability.

4. The target markets were identified in accordance with the requirements for a market to be termed as such according to The National Property Education Committe (1996), these are sufficent number of people; people with desires; people with the buying power; people who are willing to buy; people who are eligible to buy; and people who are most attracted to the marketing firm's offering.

5. Product positioning is created by making the proposed development cheaper than the competititors thus having a competitive advantage over competitors by introducting high quality finishes to influence the target consumers to position in the product, address perceptions, impressions and feelings that consumers hold for the product in comparison with competing products.

6. Product positioning was achieved by using three steps consitsing of identifying potential competitive advanatge, selecting the competitive advantage and communicating the competitive advantage by enquiring from the responednets what is it that they would prefer to be offered.

7. Positioning strategies were used to reveal the product's competitieve advanatages and desirable attributes by establishing what the prospective buyers would like to see in the product.

8. The other strategy that was used in product positioning was the benefits offered which desires to achieve customers' needs by highlighting such against other provducts in the market in order to position the product to the target market.

9. The last strategy used in the positioning was the unique selling proposition such as best quality, best services, low prices and advanced technology were all employed in order to attract the target market by establishing the features that they would want to have in the proposed house.

10. The marketing mix was developed by the application of the product (good quality house), place (convinient location), price (relatively cheap as compared to other competitors products in the market) and promotion (the efforts put in trying to position the proposed house to the prospective purchaser through a market survey/research).

\section{Recommendations}

The following recommendations are aimed at addressing the challenges and issues concomitant with this market study/research:

1. It is advisable to always establish what the market is looking for through a market research study because it will help the developer to have a product that is addressing the needs and wants of the customers thus avoiding the financial loss of not getting a buyer for the product.

2. Two segments are therefore recommended as the target markets based on the responses from the customers who were administered with a questionnaire.

3. To banks that finance developers without proper market research and business plan, they should encourage them to undertake such because it will minimise the problems of failure to pay for a loan after the development is complete and cannot attract buyers. They should always ensure that the product that they are contemplating on has demand.

4. As much as developers believe that there is demand for housing in Gaborone, this might be a challenge to implement but they should be encouraged to carry out a market research though costly to help them identify the target market (demand) for the product and perhaps increasing their market niche.

5. For institutional developers like BHC, they should also learn a lesson from this and join the band wagon because they are also fond of developing housing in areas where there is neither market nor demand. A case in point was a Francistown Housing Project which after completion houses stood vacant without buyers thus prone to vandalism in some cases.

6. Market research is the filter between the customer and the developer because it reveals what the developer has not thought would make impact on the market. It is recommended that developers should learn to get feedback about the products that they are selling or putting on the market.

7. To CEDA an organisation formed by the Act of Parliament to finance projects for Citizen Entrepreneurs, they should first establish if the developer has undertaken a market research with results that will not put the financier in an awkward position. It is highly recommended that before decisions are made, it is always advisable to check the viability of the proposed business and establish if there is a market for that particular product. 


\section{References}

Berkowitz, E. N., Kerin, R. A., \& Rudelius, W. (1989). Marketing. Homewood: Illinois: Irwin.

Botswana Review. (2014). Botswana Review of Commerce and Industry. Gaborone: B \& T Directories (Pty) Ltd.

Cravens, D. W. (1997). Strategic Marketing (5 ed.). Richard D Irwin.

Deloitte. (n.d.). Deloitte . Retrieved March 13, 2013, from Deloitte: www.deloitte.com

Kotler, P. (1998). Marketing Management: Analysis, Planning, Implementation and Control. Englewood Cliffs: Prentice Hall.

Kotler, P. (2012). Principles of Marketing (4 ed.). USA: Pearson Education.

Kotler, P., Wong, V., Saunders, J., \& Armstrong, G. (2005). Principles of Marketing (4 ed.). Spain: Pearson Education.

Kumar, P. (2010). Marketing for hospitality and tourism services. New Dehli: Tata McGraw Hill.

Leedy, P. D. (1997). Practical Research: Planning and design. New Jersey: Prentice - Hall.

Levitt, T. (1983, May - June ). The Globalisation of Markets. Harvard Business Review, pp. 92 - 102.

Matambo, K. (2010). "Transforming our economy after the crisis: 2010 and beyond" 2010 Budget Speech. Gaborone: Government Printers.

Peter, J. P., \& Olson, J. C. (1996). Consumer Behaviour and Marketing Strategy (4 ed.). USA: Times Mirror Higher Education Group.

Schoel, W. F. (1985). Marketing: Contemporay concepts and practices. Newton: MA: Allyn and Bacon.

Siong, H. C. (1994). Evaluation of housing estate development in relation to housing supply in Malaysia: The case of John Bahru Metropolitan Area. University of Toyohashi. Japan: Unpublished. PhD Thesis.

Statistics Botswana. (2010). Botswana Statistical Year Book - 2010. Gaborone: Statistics Botswana.

The National Property Education Committe. (1996). Introduction to Property Marketing. Florida: Technikon SA.

UNCTAD. (2003). Investment Policy Review - Botswana. New York: United Nations.

Wood, M. B. (2004). Marketing Planning: Principles into practice. London: Pearson Education.

World Investment Report. (2010). Retrieved June 12, 2010, from www.unctad.org/section/dite_dir/docs/wir06_fs_bw_en.pdf 